\title{
Influence of food intake but independence of body weight on puberty in female sheep
}

\author{
J. M. Suttie, D. L. Foster*, B. A. Veenvliet, T. R. Manley and I. D. Corson \\ MAFTech, Invermay Agricultural Centre, Private Bag, Mosgiel, New Zealand
}

\begin{abstract}
Summary. The effect of maintaining female sheep at a body weight intermediate between the normal weight for puberty $(30-35 \mathrm{~kg})$ and $20 \mathrm{~kg}$ (puberty suppressed) on the onset of oestrous cycles was studied. In addition, the influence of ad-libitum food intake or insulin infusion was studied in animals previously maintained at $20 \mathrm{~kg}$. Coopworth ewe lambs (10 weeks old) were allocated to one of 6 treatments: (A) adlibitum fed $(n=6)$, (B) ad-libitum fed to $28 \mathrm{~kg}$ then maintained at that weight $(n=6)$, (C) ad-libitum fed to $24 \mathrm{~kg}$ then maintained at that weight $(n=6)$, (D) maintained at $20 \mathrm{~kg}$ until Week 29 and then fed ad libitum $(n=6)$, (E) maintained at $20 \mathrm{~kg}$ and infused with $0 \cdot 1 \mathrm{U}$ insulin $/ \mathrm{kg} / 24 \mathrm{~h}$ for 2 weeks from $29-31$ weeks of age $(n=5),(\mathrm{F})$ maintained at $20 \mathrm{~kg}(n=6)$. The lambs were penned indoors under natural photoperiod, which was decreasing virtually throughout the study, and fed a pelleted concentrate diet which was recorded daily. They were blood sampled twice a week, and plasma was analysed for progesterone. Puberty was defined as the date when plasma concentrations of progesterone first exceeded $1 \mathrm{ng} / \mathrm{ml}$. In addition, ewes in Groups D, $\mathrm{E}$ and $\mathrm{F}$ were blood sampled every $10 \mathrm{~min}$ for $8 \mathrm{~h}$ on Days 0 and +12 of the insulin infusion or access to ad-libitum feeding and the plasma was analysed for luteinizing hormone (LH). All ad libitum-fed lambs in Group A exhibited puberty at a mean ( \pm s.e.m.) age of $26.1 \pm 1.8$ weeks and a weight of $44.2 \pm 2.4 \mathrm{~kg}$. Puberty was delayed 5 weeks in Group B lambs and occurred after the food required to maintain weight at $28 \mathrm{~kg}$ had been reduced from $\sim 8 \mathrm{~kg} /$ week to $4 \mathrm{~kg} /$ week. The animals in Groups $\mathrm{F}$ $(20 \mathrm{~kg}$ ), and C ( $24 \mathrm{~kg})$ did not reach puberty by 38 weeks of age, when photoperiod was increasing and thus was inhibitory for puberty. The insulin infusion (Group E) was without effect on LH or progesterone secretion but ad-libitum nutrition (Group D) caused an increase in LH secretion 6 days later and puberty in 4 of the 6 lambs 5 weeks later. It is considered that body weight per se is not a primary cue for puberty in sheep, but animals at an intermediate weight can adapt to undernutrition and achieve puberty. The mechanism of adaptation to undernutrition is not known but is unlikely to be due to a modest increase in blood insulin concentrations.
\end{abstract}

Keywords: puberty; ewe lamb; body size; food intake; growth restriction; metabolic adaptation

\section{Introduction}

Although it is almost axiomatic that plane of nutrition has an important influence on reproduction, particularly puberty, the mechanisms linking the two are poorly understood (Foster et al., 1985a). Some investigators have stressed the importance of body weight or body composition per se in determining whether a female is capable of breeding for the first time (Kennedy \& Mitra, 1963; Frisch, 1988), but others have sought more-physiological mechanisms whereby information about

*Present address: Reproductive Sciences Program, Departments of Obstetrics and Gynaecology, and Biology, The University of Michigan, Ann Arbor, MI 48109-0404, USA. 
body weight, composition and nutritional status could be transmitted to the reproductive system (Foster et al., 1985b; Cameron et al., 1985). The 'body weight' hypothesis considers that there is a critical body weight, a certain proportion of which must be fat, for puberty to occur (Frisch, 1988). In contrast, the 'metabolic hypothesis' considers that weight and fatness are consequences or correlates of metabolic changes occurring before and around the timing of puberty. According to this hypothesis, blood-borne substances signal the brain about metabolic readiness for puberty. These blood-borne signals may be metabolites, hormones or a combination (Steiner, 1987; Foster et al., 1989). The mechanism whereby growth-related cues influence the hypothalamic-pituitary axis is not well known. Steiner (1987) considered that insulin was a prime candidate for involvement, however, because insulin was suppressed by undernutrition and insulin influences the availability of substrates essential for the synthesis of neurotransmitter systems which interact with GnRH secretory mechanisms. In addition, a low-dose insulin infusion for 2 weeks can mimic the stimulatory effects of lupin feeding (supplemented protein nutrition) on ovulation rate in food-restricted ewes (Hinch \& Roelofs, 1986).

A model to test rigorously the influences of level of nutrition on luteinizing hormone (LH) secretion has been developed using sheep (Foster et al., 1985b). Ovariectomized lambs are maintained at their weaning weight of $\sim 20 \mathrm{~kg}$ by quantitative food restriction. Under these conditions, despite the lack of ovarian steroid negative feedback, the female is severely hypogonadotrophic. There is little LH secretion, as evidenced by slow frequency pulses (Foster et al., 1985b, 1989; Landefeld et al., 1989). These growth-restricted lambs respond within a few days to ad-libitum nutrition by increasing the frequency of LH pulses (Foster et al., 1989).

The present study had two aims. Firstly, we determined the effects on the onset of progesterone cycles of maintaining female lambs at a body weight intermediate between the minimum body weight normally associated with puberty $(\sim 30-35 \mathrm{~kg})$ and $20 \mathrm{~kg}$. Secondly, we tested whether an insulin infusion could replicate the reproductive effects of a high plane of nutrition in foodrestricted lambs.

\title{
Materials and Methods
}

\begin{abstract}
Animals and management. Thirty-five entire Coopworth ewe lambs were housed individually indoors in pens measuring $2 \times 1.2 \mathrm{~m}$ and fed barley, barley straw and rape seed meal with vitamins and minerals supplemented. This diet provided $9.8 \mathrm{MJ}$ metabolizable energy $/ \mathrm{kg}$ and contained $130 \mathrm{~g}$ crude protein $/ \mathrm{kg}$. No manipulations of temperature or daylength were made, and both followed the normal seasonal pattern at $45^{\circ} \mathrm{S}$. After 2 weeks of adjustment to the diet and housing conditions, on 22 December (the summer solstice in the Southern Hemisphere) the lambs were randomly allocated to one of 6 treatments: Group A, ad-libitum fed $(n=6)$; Group B, ad-libitum fed until each animal had reached $28 \mathrm{~kg}$, then fed to maintain that target weight $(n=6)$; Group C, ad-libitum fed until each animal reached $24 \mathrm{~kg}$, then maintained at that weight $(n=6)$; Group D, ad-libitum fed until each animal had reached $20 \mathrm{~kg}$ then maintained at that weight until 29 weeks of age and then fed ad libitum for the remainder of the study $(n=6)$; Group E, same as Group F but infused with insulin for 2 weeks (see below) $(n=5)$; Group F, ad-libitum fed until each animal had reached $20 \mathrm{~kg}$ then maintained at that weight $(n=6)$.

The study concluded when the lambs were 38 weeks old, which was 2 weeks after the winter solstice and well after the expected age of normal puberty at 26 weeks of age (J. M. Suttie, unpublished data).

Each lamb was weighed weekly, and the amount of feed offered was adjusted so that the weight could be carefully controlled. Food residues were collected daily to measure food intake accurately. All lambs were shorn at 14 and 29 weeks of age to reduce the contribution of the wool to the measurement of liveweight.
\end{abstract}

Blood sampling. A blood sample was withdrawn into an evacuated heparinized tube twice a week from the jugular vein of all lambs throughout the study. In addition, blood samples were collected from all lambs in Groups $D, E$ and $F$ through a jugular cannula every $10 \mathrm{~min}$ for $8 \mathrm{~h}$ on Days 0 and +12 of insulin infusion or access to ad-libitum nutrition beginning at 29 weeks of age. All lambs in Groups B and C were bled every $10 \mathrm{~min}$ for $8 \mathrm{~h}$ once during the study at 33 weeks of age.

Insulin infusion. From 29 to 31 weeks of age lambs kept at $20 \mathrm{~kg}$ (Group E) were infused through a second jugular cannula with $0 \cdot 1 \mathrm{U}$ human insulin $/ \mathrm{kg} / 24 \mathrm{~h}$ (Humulin: Eli Lilly Ltd, Auckland, New Zealand) using a Desaga Peristaltic pump. This period coincided with the first 2 weeks of ad-libitum feeding for Group D, previously held at $20 \mathrm{~kg}$. The 
dose of insulin was the same as that used by Hinch \& Roelofs (1986) to increase ovulation rate in adult ewes fed to maintenance.

Hormone analysis. LH was measured by homologous double-antibody radioimmunoassay using the method of Niswender et al. (1969) with the following modifications. The antiserum used at a final tube dilution of 1:525000 was anti-ovine LH $\$ 669$ (Pelletier et al, 1982 ), and the preparation used for iodination and as a standard was CY 1085 supplied by Dr Y. Combarnous, INRA, Nouzilly, France. This preparation has a bioactivity 3.45 times that of NIHLH-S1. The apparent sensitivity of the assay, defined as the concentration at $90 \%$ binding on the standard curve, was $0.012 \mathrm{ng} /$ tube or $0.24 \mathrm{ng} / \mathrm{ml}$ for a $50-\mu \mathrm{l}$ sample. The interassay coefficients of variation for pools of plasma containing $0.47,1.29$ and $4.98 \mathrm{ng} / \mathrm{ml}$ were $23.4 \%, 10.0 \%$ and $11.2 \%$, respectively. The intra-assay coefficients of variation for the same pools were $19 \cdot 1 \%, 4 \cdot 7 \%$ and $10 \cdot 2 \%$, respectively.

Progesterone was measured using a commercially available kit (Coat-A-Count, Diagnostic Products Corporation, Los Angeles, CA, USA). The assay sensitivity, calculated as for $\mathbf{L H}$, was $0.05 \mathrm{ng} / \mathrm{ml}$. The inter assay coefficients of variation for pools of plasma containing 1.5 and $3.2 \mathrm{ng} / \mathrm{ml}$ were $10 \%$ and $6.6 \%$ and the intra-assay coefficients of variation for the same pools were $8.4 \%$ and $7.5 \%$. The assay was validated for ovine plasma by adding known amounts of progesterone to charcoal-stripped ovine plasma. The recovery of progesterone added in concentrations of 1, 2 and $4 \mathrm{ng} / \mathrm{ml}$ was $99.7 \%, 96.8 \%$ and $94.9 \%$, respectively.

Biometric analysis. The profiles of LH were analysed separately for each lamb using the PULSAR algorithm described by Merriam \& Wachter (1982). Pulse analysis was carried out for 49 data points. Inputs for PULSAR were the expression of assay standard deviation as a function of dose $(x)$ : parameter estimates were found by regression as $\left(2 \cdot 06 x^{2}-2 \cdot 76 x+8 \cdot 44\right) / 100$. The smoothing time was set at $120 \mathrm{~min}$, the weighting factor assigned at $0 \cdot 05$ and a cut-off value of 2.7 standard deviation units was used for peak splitting. Remaining inputs were the default values suggested by Merriam \& Wachter (1982). Analysis of variance was carried out on the pulse frequency, using the GENSTAT statistical package. The criterion for the time of puberty was when plasma concentrations of progesterone first exceeded $1 \mathrm{ng} / \mathrm{ml}$. Mean liveweight and food intake data are presented \pm s.e.m. (standard error of the mean).

\section{Results}

Body weight, food intake and a schematic representation of the percentage of lambs which reached puberty are shown in Fig. 1. Lambs which were fed ad libitum (Group A) gained weight continuously throughout the study, at $\sim 170 \mathrm{~g} /$ day. Food intake increased until 17 weeks of age to $\sim 10 \mathrm{~kg} /$ week, then remained relatively constant. All lambs in this group exhibited puberty at a mean ( \pm s.e.m.) age of $26 \cdot 1 \pm 1 \cdot 8$ weeks and weight of $44.2 \pm 2.4 \mathrm{~kg}$.

Lambs which were maintained at $28 \mathrm{~kg}$ (Group B) reached that target weight by 18 weeks of age. Food intake was greatest from Weeks 15 to 17. The amount of feed required to maintain weight at $28 \mathrm{~kg}$ then steadily decreased to below $4 \mathrm{~kg} /$ week at 26 weeks of age. Shearing at Week 29 caused a transient increase in the amount of feed required to maintain the $28 \mathrm{~kg}$ weight. Of the 6 lambs, 5 attained puberty at a mean age of $31 \cdot 6 \pm 1 \cdot 3$ weeks, some 5 weeks later on average than the ad-libitum-fed Group A lambs (unpaired $t$-test, $P<0.05$ ). The group maintained at $24 \mathrm{~kg}$, Group C, reached that weight by 18 weeks of age at the same time as the $28 \mathrm{~kg}$ group reached their target weight. Food intake was highest for the $24 \mathrm{~kg}$ group at that time. The amount of feed required for maintenance decreased from 18 to 27 weeks of age, before it rose slightly after shearing. No lambs from this group reached puberty.

The remaining 3 groups (D, E and F) were successfully held at the target weight of $20 \mathrm{~kg}$ (Fig. 1, panels 4-6). Group D lambs which were re-fed beginning at 29 weeks of age grew at a rate of $190 \mathrm{~g} /$ day, and voluntary food intake rose concomitantly. Of the 6 lambs, 4 exhibited puberty at $33.9 \pm 0.6$ weeks of age, at a mean weight of $27.9 \pm 0.7 \mathrm{~kg}$. The remaining 2 anovulatory lambs were smaller $(25.9$ and $26.1 \mathrm{~kg})$ at the end of decreasing daylength at 36 weeks of age. The $20 \mathrm{~kg}$ held groups with (Group E) or without (Group F) insulin infusion required progressively less feed to maintain weight from Weeks 22 to 29 , before the transient shearing-induced rise. None of the 11 lambs in either group exhibited puberty.

The increase in LH pulse frequency (the mean of the difference in LH pulse frequency between Days 0 and 12 calculated for each lamb) after ad-libitum feeding for 2 weeks (Group D), insulin infusion for 2 weeks (Group E) or continued dietary restriction (Group F) was 1.0, 0.2 and 


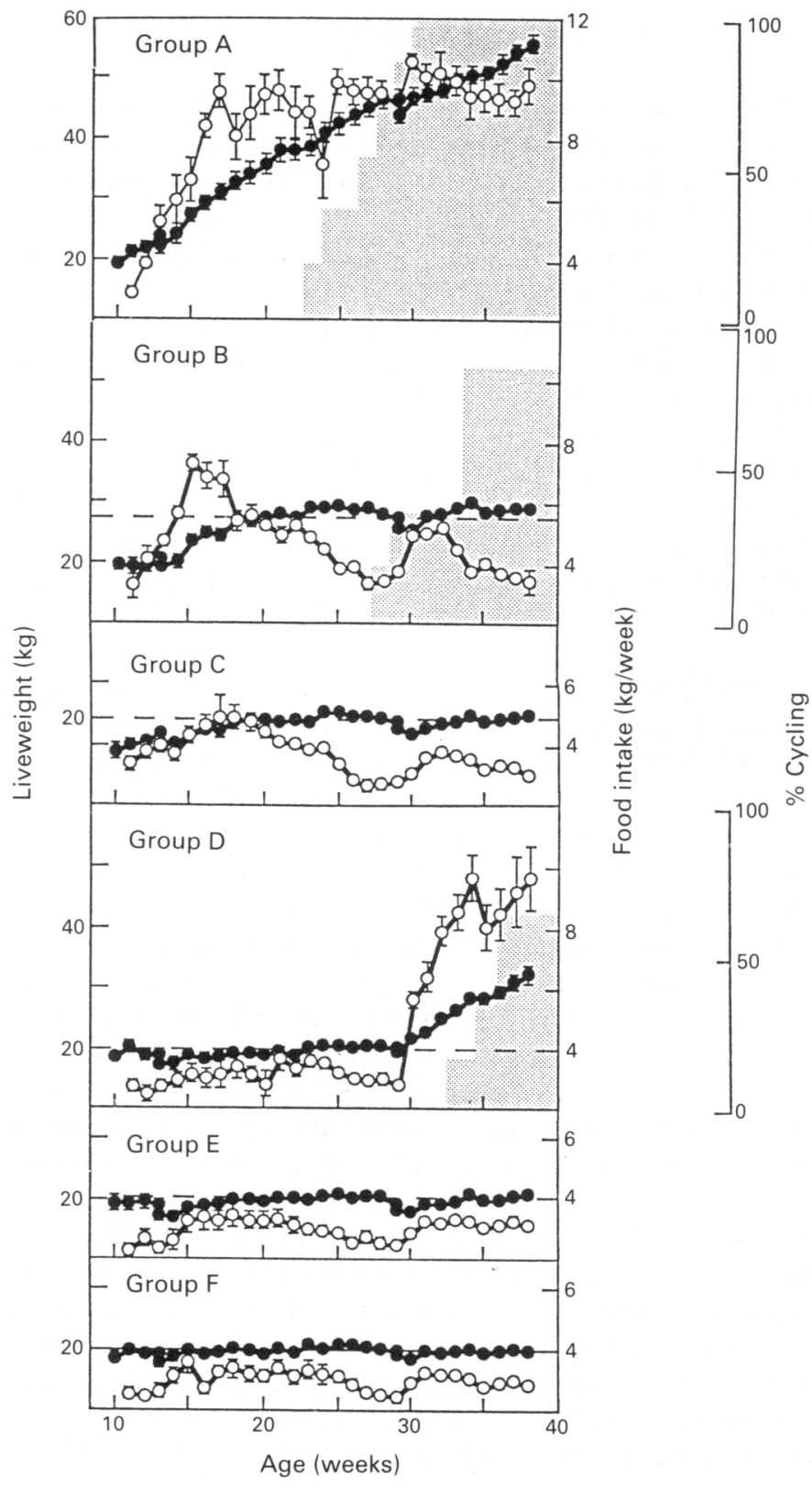

Fig. 1. Liveweight $(O)$ and food intake $(O)$ of lambs in Groups A-F and the percentage of lambs having cycles of progesterone (shaded area). Data presented for liveweight and food intake are means \pm s.e.m. The horizontal line in the panels for Groups B, C, D and E indicates the predetermined weight for each group. The experiment began on the longest day, and so daylength was decreasing for all but the last 2 weeks of the study.

0 pulses $/ 8 \mathrm{~h}$ (standard error of the difference $=0.322$ ). Only ad-libitum feeding significantly $(P<0.05)$ raised LH pulse frequency. The LH pulse frequency was significantly higher $(P<0.05)$ in the group maintained at $28 \mathrm{~kg}$ (Group B) than in the group held at $24 \mathrm{~kg}$ (Group C) (1.67 and 0.67 pulses $/ 8 \mathrm{~h}$, respectively, s.e.d. $=0.45$ ). 


\section{Discussion}

Both internal (growth nutritional state) and external (photoperiod) determinants time puberty in the female sheep (Foster et al., 1986; Foster, 1988). In well-nourished, and therefore rapidly growing, females the timing of puberty is primarily determined by photoperiod. In contrast, undernourished lambs are able to monitor daylength, but they are unable to respond to stimulatory photoperiods. In the present study, ad-libitum-fed lambs attained puberty earlier and at a larger body weight than did those of the other experimental groups. In contrast, the undernourished lambs in the 20-kg-held (Group D) and the 24-kg (Group C) groups did not receive internal cues necessary to initiate puberty. Puberty was delayed in the $28-\mathrm{kg}$-held group (Group B), compared with the ad-libitum group, probably because the internal cues indicated that physiological development was insufficient when the photoperiod first became stimulatory. The animals in Group D which were fed ad libitum after a period of undernutrition reached puberty when they attained a weight of $\sim 28 \mathrm{~kg}$; this represents a clear delay in puberty compared with the ad-libitum-fed group. Taken together, the results of these studies conducted in the Southern Hemisphere in lambs of the Coopworth breed are in accord with previous data derived from the Suffolk breed in the Northern Hemisphere (Foster, 1988), underlining the relevance of both internal and external cues in timing puberty.

If body weight were the principal measure of nutritional status providing the internal cue necessary to time puberty, the lambs held at $28 \mathrm{~kg}$ would have exhibited puberty at the same time as the ad-libitum-fed controls. The photoperiod was clearly stimulatory for puberty, and a $28-\mathrm{kg}$ body weight is sufficient for puberty. However, puberty was delayed. This is contrary to the "body weight hypothesis' (Frisch, 1988), which predicts simultaneous puberty for both groups assuming body composition was comparable. Clearly some changes must have occurred, despite the lack of weight change in the 28-kg group (Group B), which facilitated puberty. One such change is the decrease in food intake necessary to maintain weight. This might be an indicator of one or more metabolic adaptations to the imposed, progressively decreasing, nutritional regimen, as the animal attempted to adjust to the food restriction. The identity of the metabolic adaptations must remain speculative, but could include a reduction in basal metabolic rate (BMR) to decrease energy output, an increase of digestive efficiency to utilize better the food available or an alteration in nutrient partitioning within the body. It is also possible that any fat reserves present when the animal first reached $28 \mathrm{~kg}$ would be reduced during the period of weight stasis; however, body composition was not measured in the present study.

Steiner (1987) pointed out that an individual must be in positive energy balance to exhibit puberty. An animal at constant weight is, in theory, neither in positive nor negative energy balance. However, could it, by using any or all of the above metabolic adaptations, have the ability to so partition nutrients that energy is available for reproduction? This would imply that body growth could be deferred or prevented to permit reproduction. In the present study, lambs maintained at $28 \mathrm{~kg}$ began cycles of progesterone after the amount of feed required for maintenance had decreased by about half from the amount initially required when the female first reached $28 \mathrm{~kg}$. We infer that such lambs had reached their limit in terms of metabolic adaptations to undernutrition, had ceased to attempt to grow and were using energy for reproduction. In contrast, the lambs held at $24 \mathrm{~kg}$ (Group C) and $20 \mathrm{~kg}$ (Group F) similarly reduced their food intake in the same way as the 28-kg lambs, but they did not exhibit puberty. Perhaps, either their capacity for adaptation to low nutrition is less than that of those maintained at $28 \mathrm{~kg}$ or the absolute amount of food necessary for maintenance $(3 \mathrm{~kg} /$ week and $2 \mathrm{~kg} /$ week for the $24-$ and $20-\mathrm{kg}$ lambs, respectively) is insufficient to provide a positive internal signal to the reproductive system that puberty could be initiated regardless of metabolic adaptations.

The lambs were shorn twice during the study because it was felt that the increasing weight of wool would interfere with experimental weight control. Wool contributes to liveweight, but is not part of the body tissues which require energy for maintenance (Bigham, 1986). This would lead to a 
progressive error, because the proportion of the body tissue component would decrease, as wool growth increased, in the measurement of liveweight. However, the second shearing particularly caused a sharp increase in food intake in all animals, although 2 lambs in Group B had exhibited puberty before shearing. This indicates that shearing was not the likely cause of the onset of progesterone cycles. Food intake for maintenance had returned to the preshearing level by the close of the trial.

The resumption of ad-libitum feeding after a period of nutritional restriction resulted in puberty in 4 of 6 lambs (Group D). The finding that LH concentrations rose after 12 days of ad-libitum feeding agrees well with Foster et al. (1989) who found the same effect in ovariectomized lambs. The smaller effect in the present study of increased nutrition on LH pulse frequency is probably due to the compensatory presence of oestradiol negative feedback from the ovary, which is not present in ovariectomized lambs. Steiner (1987) considered insulin a prime contender for a blood-borne factor which might provide nutritional information to the reproductive endocrine system. However, in the present study, insulin was without effect on LH secretion (Group E). Although this could be due to too low a dose of insulin it was the same as that which Hinch \& Roelofs (1986) had shown could increase ovulation rate in adult cycling ewes fed to maintenance. An alternative explanation is that increased insulin concentrations alone are an insufficient internal cue of nutritional status in lambs. The results of our study do not refute the suggestion of Steiner (1987), but we consider that insulin alone, in the absence of an adequate level of nutrition, is not capable of providing a positive signal about metabolic status to the reproductive system. Alternatively, the fact that the lambs were shorn before the insulin infusion might have interfered with their response. However, as food intake actually rose during insulin infusion, it might also be thought that this would have reinforced a possible positive effect of insulin.

We thank Dr Roger Littlejohn for the biometric analysis. The study was supported by the New Zealand Ministry of Agriculture and Fisheries and a grant from the New Zealand-United States of America Scientific and Technical Co-operative Agreement.

\section{References}

Bigham, M.L. (1986) Principles of wool growth. In Sheep Production: Volume 2, Feeding Growth and Health, pp. 57-74. Eds S. N. McCutcheon, M. F. McDonald \& G. A. Wickham. New Zealand Institute of Agricultural Science, Wellington.

Cameron, J.L., Hansen, P.D., McNeil, T.H., Koerker, D.J., Clifton, D.K., Rogers, K.V., Bremner, W.J. \& Steiner, R.A. (1985) Metabolic cues for the onset of puberty in primate species. In Adolescence in Females, pp. 59-78. Eds C. Flamigni, S. Venturoli \& J. Givens. Year Book Medical Publishers, Chicago.

Foster, D.L. (1988) Puberty in the female sheep. In The Physiology of Reproduction, pp. 1739-1762. Eds E. Knobil \& J. D. Neill. Raven Press, New York.

Foster, D.L., Olster, D.H. \& Yellon, S.M. (1985a) Neuroendocrine regulation of puberty by nutrition and photoperiod. In Adolescence in Females: Endocrinological Development and Implications on Reproductive Function, pp. 1-21. Eds C. Flamigni, S. Venturoli \& J. Givens. Year Book Medical Publishers, Chicago.

Foster, D.L., Yellon, S.M. \& Olster, D.H. (1985b) Internal and external determinants of the timing of puberty in the female. $J$. Reprod. Fert. 75, 327-344.

Foster, D.L., Karsch, F.J., Olster, D.H., Ryan, K.D. \& Yellon, S.M. (1986) Determinants of puberty in a seasonal breeder. Recent Prog. Horm. Res. 42, $331-384$.

Foster, D.L., Ebling, F.J.P., Micka, A.F., Vannerson, L.A., Bucholtz, D.C., Wood, R.I., Suttie, J.M. \& Fenner, D.E. (1989) Metabolic interfaces between growth and reproduction. I. Nutritional modulation of gonadotropins, prolactin and growth hormone secretion in the growth-limited female lamb. Endocrinology 125, 342-350.

Frisch, R.E. (1988) Fatness and fertility. Scientific American 258, 88-95.

Hinch, G.N. \& Roelofs, J.H.W. (1986) Lupin feeding and insulin infusion during the late luteal phase can increase ovulation rate in sheep. Proc. Aust. Soc. Reprod. Biol. 18, 43.

Kennedy, J.P. \& Mitra, J. (1963) Body weight and food intake as initiating factors for puberty in the rat. $J$. Physiol., Lond. 166, 408-418.

Landefeld, T.D., Ebling, F.J.P., Suttie, J.M., Vannerson, L.A., Padmanabhan, V., Beitens, I.Z. \& Foster, D.L. (1989) Metabolic interfaces between growth and reproduction. II. Characterization of changes in messenger ribonucleic acid concentrations of gonadotrophin subunits, growth hormone and prolactin in nutritionally growth limited lambs and the differential 
effects of increased nutrition. Endocrinology 125 , 35!-356.

Merriam, G.R. \& Wachter, K.W. (1982) Algorithms for the study of episodic hormone secretion. Am. J. Physiol. 243, E310-E318.

Niswender, G.D., Reichert, L.E. Jr, Midgley, A.R., Jr \& Nalbandov, A.V. (1969) Radioimmunoassay for bovine and ovine luteinizing hormone. Endocrinology 84, $1166-1173$.
Pelletier, J., Garnier, D.M., de Reviers, M.M., Terqui, M. \& Ortavant, R. (1982) Seasonal variation in $\mathrm{LH}$ and testosterone release in rams of 2 breeds. J. Reprod. Fert. 64, 341-346.

Steiner, R.A. (1987) Nutritional and metabolic factors in the regulation of reproductive hormone secretion in the primate. Proc. Nutr. Soc. 46, 159-175.

Received 9 April 1990 